Cutaneous metastases of bladder carcinoma are very rare. The rate of cutaneous metastasis in urologic malignancies is $1.3 \%$ and this rate was found to be $0.84 \%$ for bladder carcinomas. Cutaneous metastasis of bladder carcinoma can be confused with cellulitis. This case report presents a 60-year-old patient operated on for bladder carcinoma and undergoing treatment for cellulitis because of erythematous lesions appearing in the suprapubic region in the early postoperative period. As there was no response to antibiotic treatment, skin biopsy was performed and cutaneous metastasis was diagnosed. Subsequently, chemotherapy with carboplatin and gemcitabine was started. The prognosis of bladder carcinoma with cutaneous metastasis has been reported to be poor.

Key words: bladder carcinoma, cutaneous and subcutaneous metastasis, cellulitis.

\section{Cutaneous and subcutaneous metastases from bladder carcinoma}

\author{
Ahmet Dirican'1, Yüksel Küçükzeybek ${ }^{1}$, Ișıl Somalı1, Çiğdem Erten ${ }^{1}$, \\ Lütfıye Demir ${ }^{1}$, Alper Can ${ }^{1}$, ỉbrahim Vedat Bayoğlu, ${ }^{1}$, Murat Ermete ${ }^{2}$, \\ Ayșegül Aksoy Altınboğa², Mustafa Oktay Tarhan ${ }^{1}$
}

${ }^{1}$ Medical Oncology Clinic, Izmir Atatürk Training and Research Hospital, Izmir, Turkey 2Pathology Clinic, Izmir Atatürk Training and Research Hospital, Izmir, Turkey

\section{Introduction}

Cutaneous and subcutaneous metastases of bladder carcinoma are extremely rare. Bladder carcinoma most commonly metastasizes to the lymph nodes, liver, lungs and bones. Generally rates of cutaneous metastases of malignancies have been reported as $1.02 \%, 5.3 \%$ and $2.9 \%$, respectively in 3 large series [1-3]. In these series, cutaneous metastases were most commonly reported for breast cancer. Cutaneous spread from primary urologic malignancies was reported to have a rate of $1.3 \%$ and this rate was $0.84 \%$ for bladder carcinoma [3]. Cutaneous metastasis from bladder carcinoma occurs most commonly to the locoregional area and via lymphatic drainage [4, 5]. Cutaneous metastases can be in many forms such as erysipeloid, nodular and inflammatory. Cutaneous metastases of urologic malignancies are known to show poor prognosis [3].

\section{Case report}

The 60-year-old male patient underwent radical cystoprostatectomy on January $15^{\text {th }}$, 2011. Histopathological examination revealed a high grade (grade 3) invasive urothelial carcinoma (pT4aNXMO). Surrounding the tumor, there was diffuse vascular embolus and perineural invasion (Fig. 1A). Distant metastases were not noted in abdominal MRI and thorax CT. In the first postoperative month erythematous papular lesions developed in the suprapubic region. They had erysipeloid appearance (Fig. 2). Physical examination revealed edema and clinically there was pain and leucocytosis and high levels of $C$ reactive protein (CRP) were found in the peripheral blood. Suprapubic ultrasound was carried out. It revealed cutaneous and subcutaneous edema and there were numerous lymph nodes up to $3 \mathrm{~cm}$ in diameter in this region. Infection was primarily considered; thus antibiotic treatment with piperacillin-tazobactam was started. While leucocytosis improved, there was no improvement in the lesions or CRP levels, so a punch biopsy was taken from the lesions. Histopathology revealed carcinoma metastasis. Immunohistochemically, tumor cells were cytokeratin (CK) 7, CK 20 positive. It was considered to be cutaneous metastasis of bladder carcinoma and chemotherapy with carboplatin and gemcitabine was started.

\section{Discussion}

Cutaneous metastasis of bladder carcinoma is more commonly seen in the male population [3]. Cutaneous metastasis can be the first finding of bladder carcinoma and clinically it can be confused with cellulitis [6]. However, it can be differentiated with skin biopsy. Also in our case, antibiotic treatment was primarily administered because of the picture of cellulitis and when a complete response could not be obtained skin biopsy was performed, revealing metastasis. Immunohistochemically positive cytokeratin expressed from the uroepithelial tissue in skin biopsy can be useful in differential diagnosis. More than $90 \%$ of bladder carcinoma cases with cutaneous metastasis consist of transitional cell histopathol- 

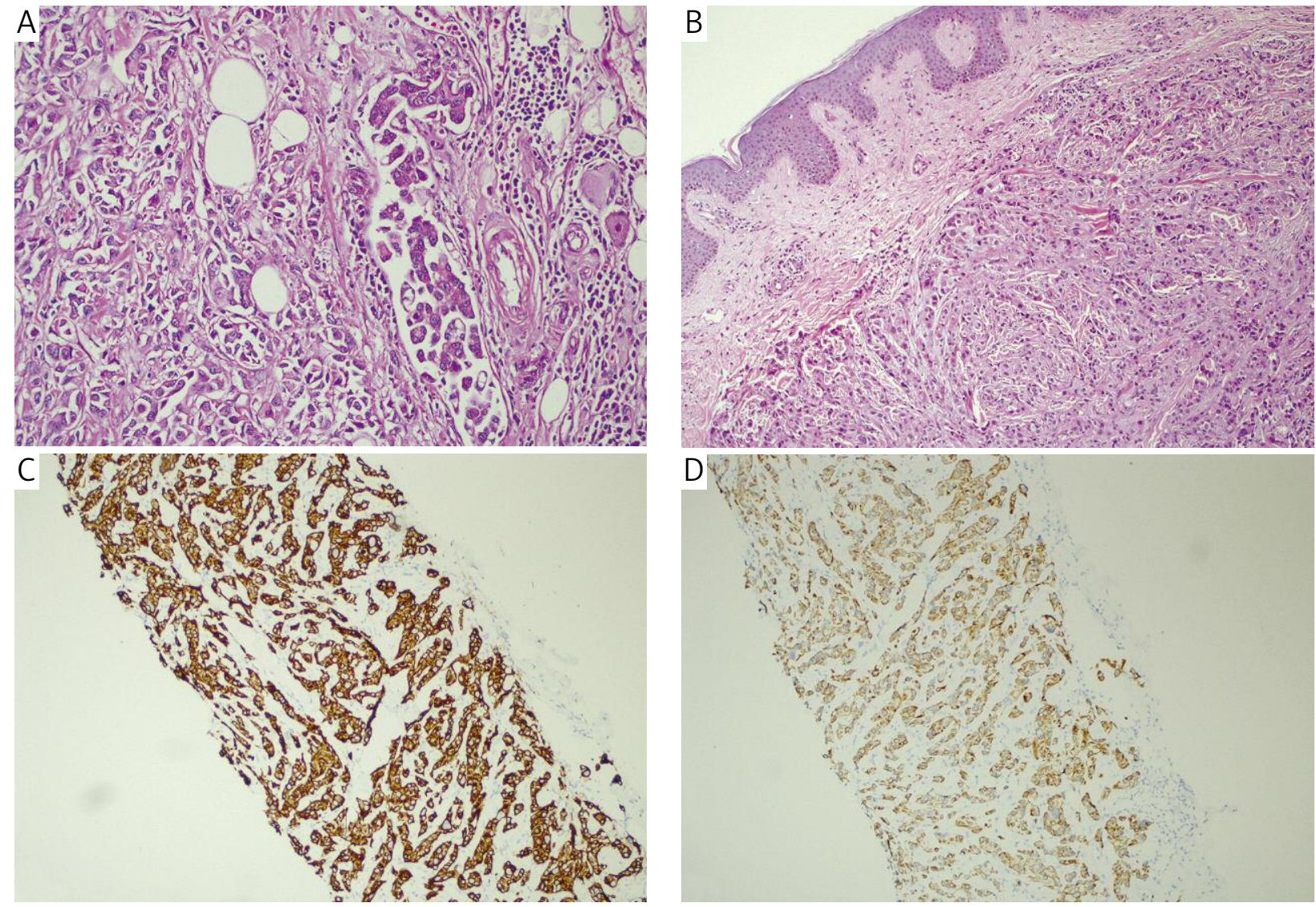

Fig. 1. A - perivesical adipose tissue invasion and vascular invasion in cystectomy material; B - solid tumor areas within the epidermis; C - CK 7 positivity, D - CK 20 positivity

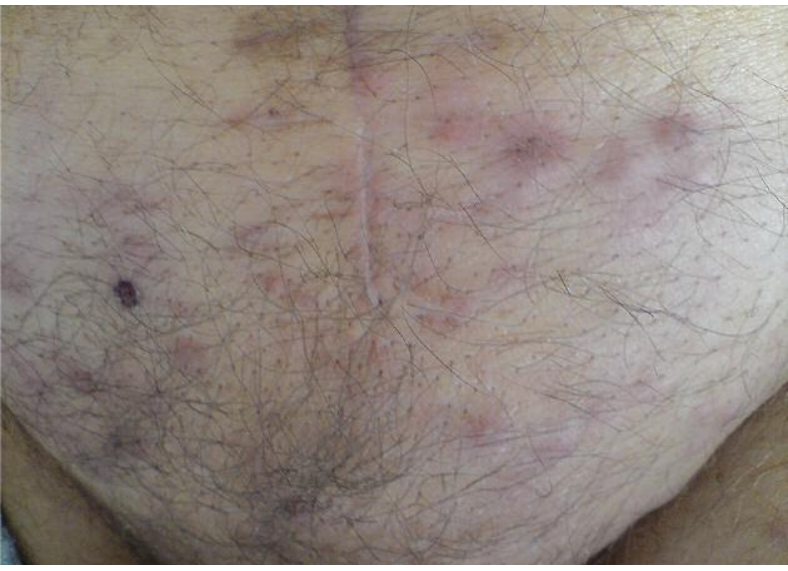

Fig. 2. Erythematous papular lesions in the suprapubic region

ogy [7]. There are options of radiotherapy and chemotherapy for cutaneous metastases [3, 8]. Despite treatment, cutaneous metastasis of bladder carcinoma is an indicator of poor prognosis; median disease-specific survival is less than 6 months $[3,8]$. In conclusion, it should be kept in mind that erythematous lesions in the suprapubic region can belong to the cutaneous metastasis of bladder cancer in particular. Skin biopsy should be performed for differential diagnosis and chemotherapy should be started considering that these patients have a poor prognosis if metastasis is found.

The authors declare no conflict of interest.

\section{References}

1. Hu SC, Chen GS, Wu CS, Chai CY, Chen WT, Lan CC. Rate of cutaneous metastases from different internal malignancies: experience from a Taiwanese medical center. J Am Acad Dermatol 2009; 60: 379-87.

2. Krathen RA, Orengo IF, Rosen T. Cutaneous metastasis: a meta-analysis of data. South Med I 2003; 96: 164-7.

3. Mueller TJ, Wu H, Greenberg RE, Hudes G, Topham N, Lessin SR, Uzzo RG. Cutaneous metastases from genitourinary malignancies. Urology 2004; 63: 1021-6.

4. Saito S. Solitary cutaneous metastasis of superficial bladder cancer. Urol Int 1998; 61: 126-7.

5. Hollander A, Grots IA. Oculocutaneous metastases from carcinoma of the urinary bladder. Case report and review of the literature. Arch Dermatol 1968; 97: 678-84.

6. Cohen E, Kim SW. Cutaneous manifestation of carcinoma of urinary bladder: carcinoma erysipelatoides. Urology 1980; 16: 410-2.

7. Mostofi FK, Davis CJ, Sesterhenn IA. Pathology of tumors of the urinary tract. In: Skinner DG, Lieskovsky G (eds.). Diagnosis and Management of Genitourinary Cancer. WB Saunders, Philadelphia 1988; 83-117.

8. Akman Y, Cam K, Kavak A, Alper M. Extensive cutaneous metastasis of transitional cell carcinoma of the bladder. Int J Urol 2003; 10: 103-4.

\section{Address for correspondence}

\section{Mustafa Oktay Tarhan}

Izmir Atatürk Training and Research Hospital

Medical Oncology Clinic

35360 Izmir

Turkey

tel. +90232 2434343

e-mail: motarhan@yahoo.com

Submitted: 27.09 .2011

Accepted: $\quad 4.10 .2012$ 